\title{
Psychosocial Profile of HIV Patients on HAART in Southern India
}

\author{
Jayakumar Palanisamy ${ }^{1}$, Karthikeyan Murugesan', Senthilkumar Subramanian ${ }^{3}$, Uma Devi ${ }^{4}$, \\ Pitchai Chinnapidaran ${ }^{4}$, Rajamahendravarman Vellandi ${ }^{4}$, Inigo Beula ${ }^{4}$
}

${ }^{1}$ Primary Health Center, Pollachi, India; ${ }^{2}$ Department of Psychiatry, Govt Rajaji Hospital, Madurai, India; ${ }^{3}$ Department of Public Health and Preventive Medicine, Coimbatore, India; ${ }^{4}$ AntiRetroviral Therapy (ART) Center, Govt Rajaji Hospital, Madurai, India. E-mail: drjayakumar1999@gmail.com

Received October $16^{\text {th }}, 2011$; revised November $24^{\text {th }}, 2011$; accepted December $1^{\text {st }}, 2011$.

\begin{abstract}
Background: Mortality of HIV/AIDS patients comes down in India after the National Aids Control Organization started providing free Antiretroviral Therapy (ART) since 2004. Madurai ART Center started providing free ART since 2004. Psychosocial profile of this population explored in this study. Methods: A cross sectional interview conducted during the year 2008 with semi structured questionnaire on HIV positive clients who are on Highly Active Anti-Retroviral Therapy (HAART) for more than 6 months. Convenience sampling done and totally 433 clients were interviewed with informed consent. Results: Three fourth (73.4\%) of the clients know about ART centre through Government Hospitals or Primary Health Centre. Most of the Clients (98.6\%) on ART feel back to normal life or back to near normal life. Pill burden/Pill fatigue perceived by clients is $4.8 \%$. Discrimination perceived was $8.8 \%$ and mostly in their own house or by neighbors, but most of their children (99.2\%) were not discriminated as per the clients. Spouse positive rate for the married clients was $61.5 \%$ and unmarried in this population was $4.6 \%$. Major or minor psychological problems in this group were $39.7 \%$ and attempted suicide was $8.8 \%$. Drug abuse (alcohol and smoking) while started on ART was 40.4\% and the current abusers are 7.6\%. Conclusion: This study supports effectiveness of free ART program and effective case referral from government institutions. High percentage of major or minor psychological problem warrants further exploratory study and may need psychological interventions in this population.
\end{abstract}

Keywords: HIV, AIDS, Antiretroviral Therapy, Psychosocial

\section{Background}

In India since 2004 with the availability of free HAART in government program [1] through National AIDS Control Organization (NACO), people living with HIV/AIDS keep on increasing. In south India, Madurai ART centre which is having around 2500 clients on ART and regular follow-up, out of these 433 clients on ART are interviewed to find out their demographics, psychological disturbances, and adherence to HAART, etc during the year 2008.

\section{Methodology}

With convenience sampling a cross sectional survey was conducted with semi structured questionnaires on HIV/AIDS patients who are all on ART more than 6 months. Clients interviewed are more than 21 years of age. Questionnaire administered includes questions regarding psychological, social, personal and family issues of the clients. Participants should not have any major clinical illness which might discomfort during the interview and their quality of life.

\section{Results}

Among the interviewed clients (51.3\% males, $48.7 \%$ females) $95.8 \%$ of them are in 21 to 50 years of age group. Positive clients from rural population is $44.8 \%$ and urban/semi urban population is $55.2 \%$.

Totally $75.8 \%$ of the clients were education wise illiterate or with in primary school. $58.4 \%$ of the clients are daily wage laborers (Cooley's) and $19.6 \%$ of the clients are unemployed. $58.4 \%$ of the clients are living with their spouses and $33.7 \%$ of them are separated or widowed. Unmarried and divorced are $4.6 \%$ \& $3.2 \%$ respectively. Most (94.7\%) of them are getting their economical support by their own, spouses or by their relatives.

Spouses of these clients $61.5 \%$ of them are positive. In the positive spouses $35.4 \%$ of male spouses and $64.6 \%$ of 
the female spouses are positive. In spouse negative clients $83 \%$ of male spouses are negative and $17 \%$ of the female spouses are negative (Figure 1).

In the study population $73.4 \%$ of the clients were known about ART centre through Government Hospitals (GH) or Primary Health Centre (PHC), 14\% through Non Governmental Organization (NGO) and 11\% by their own (Figure 2). This shows how they registered into ART program..

Among the clients $15.9 \%$ of them are traveling more than 100 kilometers to collect their monthly drugs. $22.2 \%$ of the clients were missed some doses of drug during their regular follow up period, among the total clients $4.6 \%$ of them were missed more than 3 days (Figure 3).

As per their own perception $8.8 \%$ of these clients were discriminated mainly in their own house or by neighbors (Figure 4). But the children of these positive clients were rarely $(0.8 \%)$ discriminated.

Major (Suicidal thought) or minor psychological (Sleep disturbances, sad mood, lack of concentration in their work) problems were seen in $39.7 \%$ of the clients (Figure 5).

Pill burden/Pill fatigue perceived in this population is $4.8 \%$. Drug abusers (smoking, alcohol, sleeping pills) in this population were $40.4 \%$ and the current abusers are $7.6 \%$. In this population $8.8 \%$ of them were having the history of attempted suicide. Clients having children were $86 \%$, among them $7.8 \%$ of the clients are having positive children and $30.4 \%$ of them were not yet tested. Among these clients having children $40 \%$ worried about future of their children and $36.6 \%$ of them want to send their children to some care takers.99.2\% of their children were not discriminated as per the clients. Qualitatively, 98.6\% of clients on ART are perceived that they are "back to normal life" or "back to near normal life" (Figure 6).

\section{Discussion}

The active, productive and reproductive age group (21 to 50 years) is the majority on HAART, which is the target group (15 to 49) in prevention strategies [2]. Transmission of HIV in this population is mainly through males, which can be substantiated by male dominated society [3]. High rate widowed/separated population urges to promote remarriage and supporting strategies [4]. Around $16 \%$ of the clients were traveling more than $100 \mathrm{kms}$ to collect their drugs which may be due to lack of ART centers nearby or avoidance of nearby ART centers due to self stigma [5]. Three fourth of the clients were illiterate

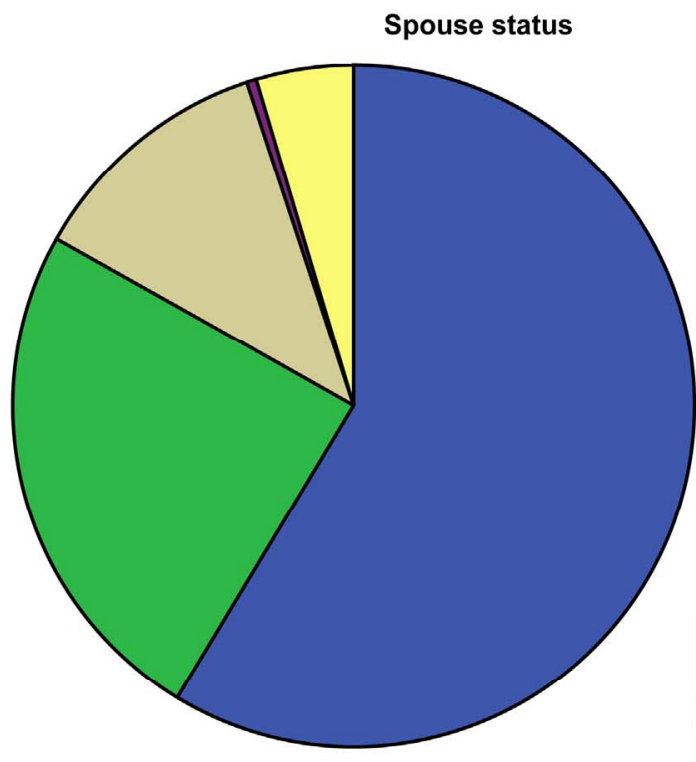

\begin{tabular}{|l|l|r|r|r|}
\hline \multicolumn{2}{|l|}{ HIV status of spouse } & Frequency & Percent & $\begin{array}{c}\text { Valid } \\
\text { Percent }\end{array}$ \\
\hline & Positive & 254 & 58.7 & 61.5 \\
\hline & Negative & 106 & 24.5 & 25.7 \\
\hline & Not tested & 51 & 11.8 & 12.3 \\
\hline & Indeterminate & 2 & 0.5 & 0.5 \\
\hline & Total & 413 & 95.4 & 100.0 \\
\hline Missing & Unmarried & 20 & 4.6 & \\
\hline Total & 433 & 100.0 & \\
\hline
\end{tabular}

Figure 1. HIV status of the spouses, as per the interviewed clients. 


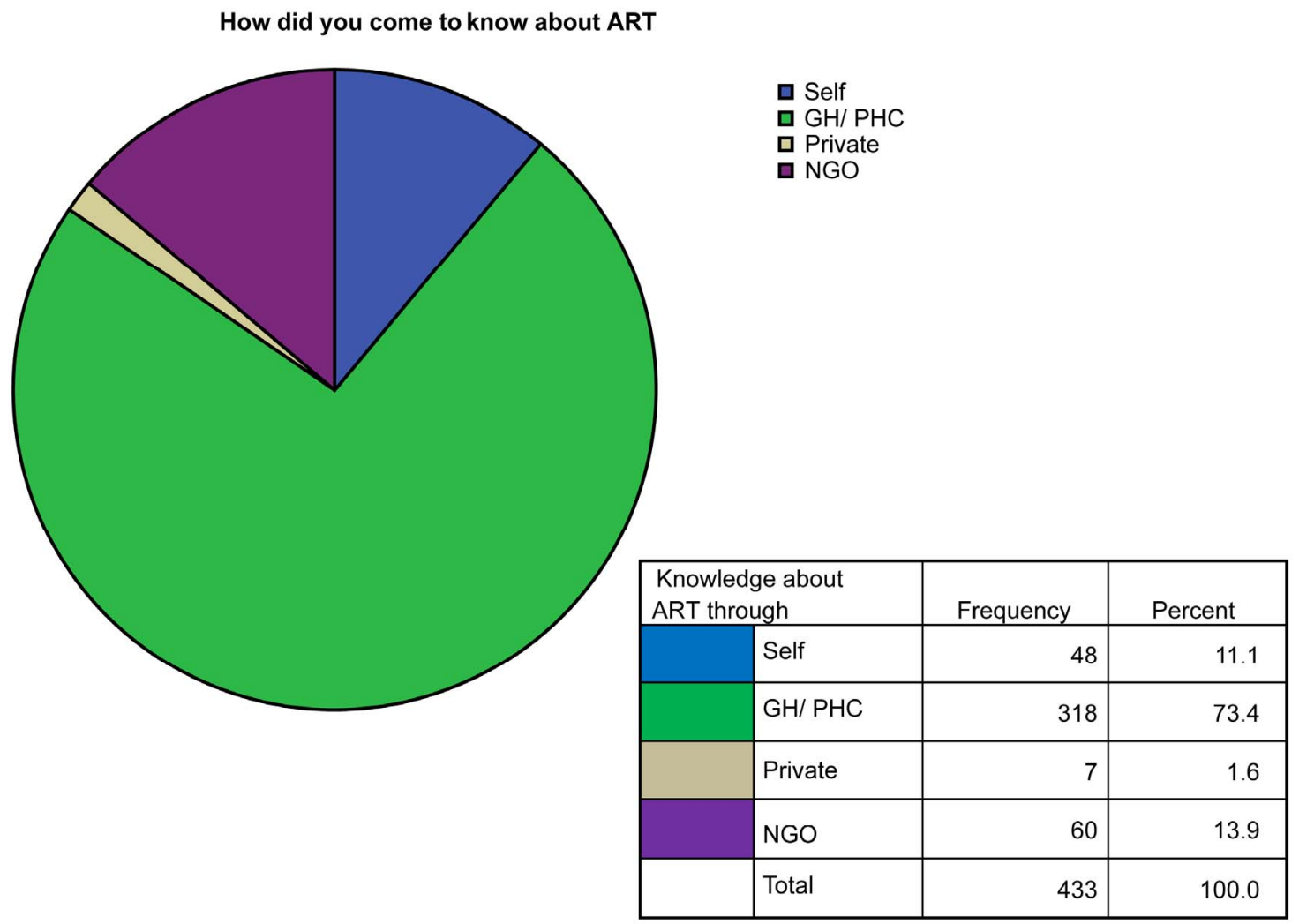

Figure 2. Client's knowledge about ART centre.

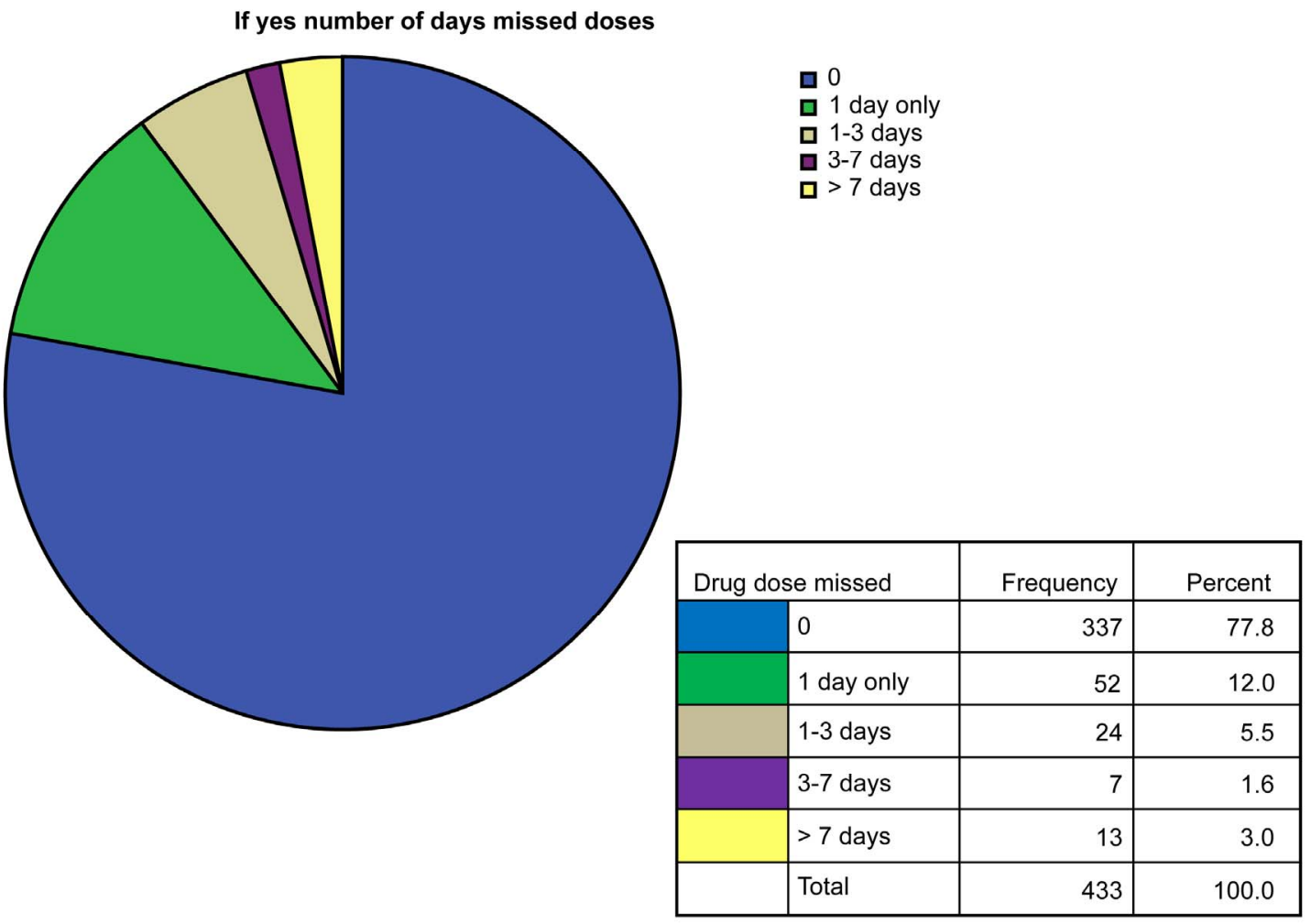

Figure 3. Missed doses of ART drugs as per the clients and records. 


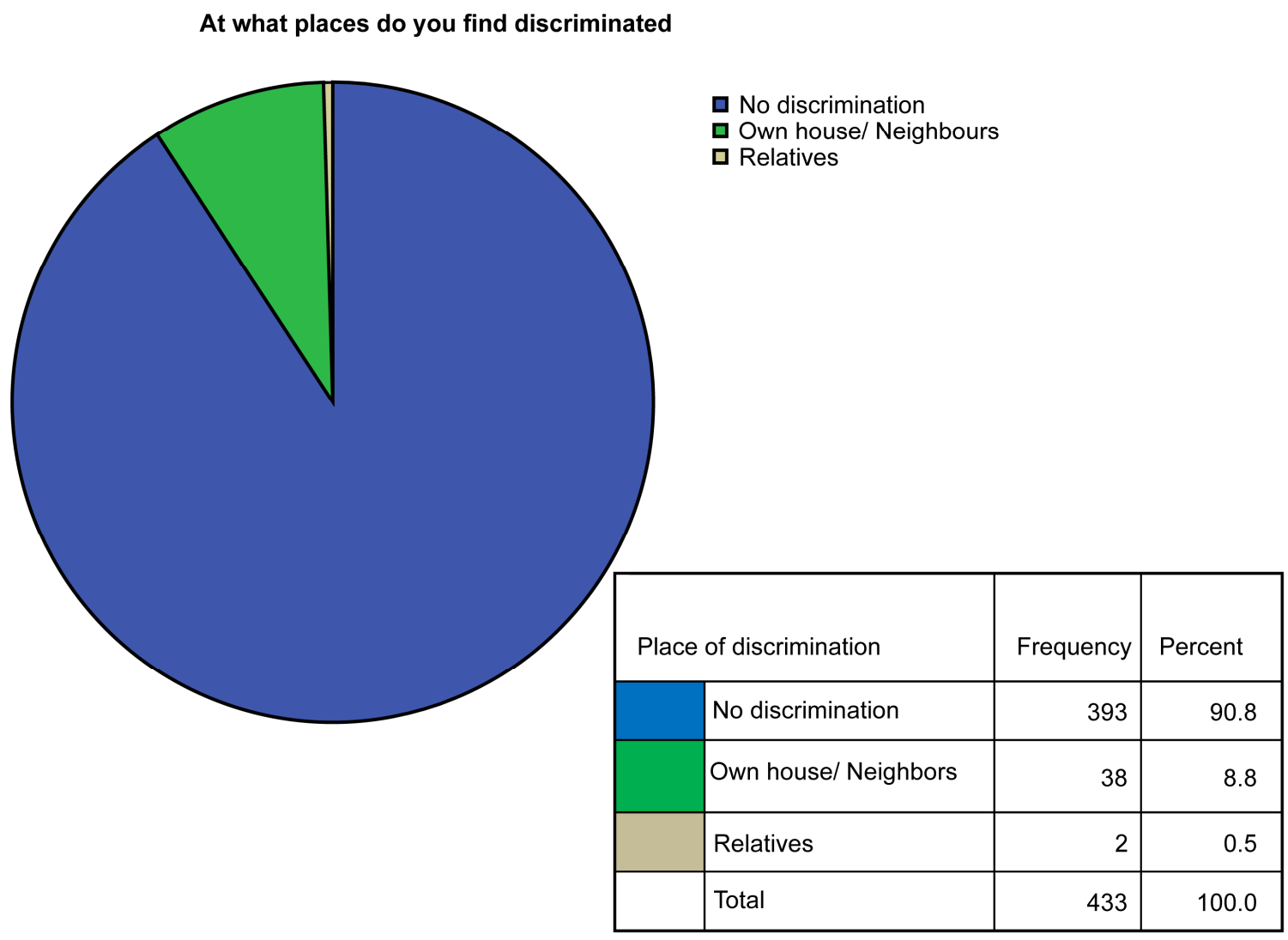

Figure 4. Showing where these clients perceived discrimination.

Do you have any psychological problems

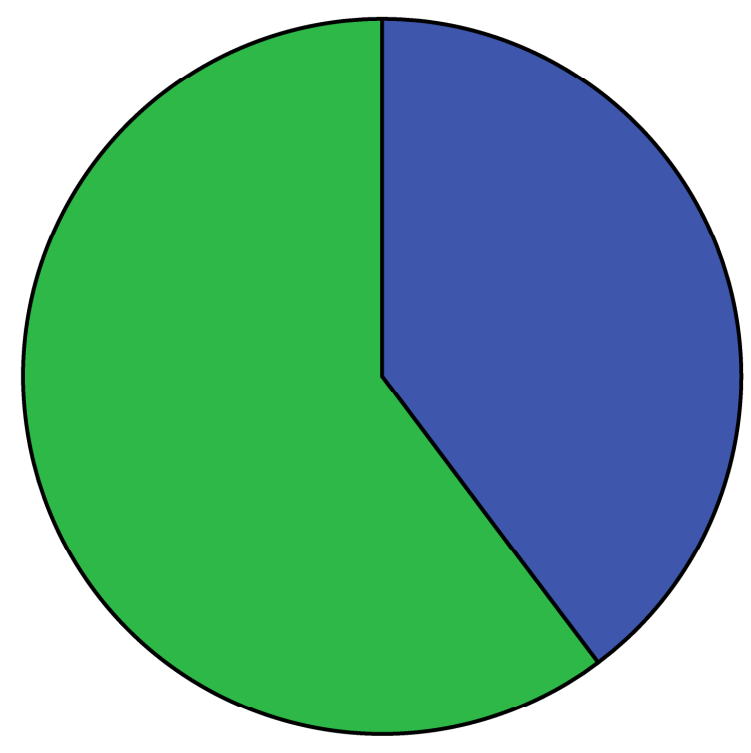

व Yes
$\square$ No
\begin{tabular}{|l|l|r|r|}
\hline $\begin{array}{l}\text { Psychological } \\
\text { problem }\end{array}$ & Frequency & Percent \\
\hline & Yes & 172 & 39.7 \\
\hline & No & 261 & 60.3 \\
\hline & Total & 433 & 100.0 \\
\hline
\end{tabular}

\begin{tabular}{|l|r|r|}
\hline Type of psychological problem & \multicolumn{2}{|c|}{ Yes } \\
\hline & Count & \multicolumn{1}{c|}{$\%$} \\
\hline Sleep disturbance & 113 & $26.1 \%$ \\
\hline Lack of concentration in work & 33 & $7.6 \%$ \\
\hline Sad mood & 58 & $13.4 \%$ \\
\hline Suicidal thoughts & 25 & $5.8 \%$ \\
\hline
\end{tabular}

Figure 5. Psychological problems perceived by the clients. 


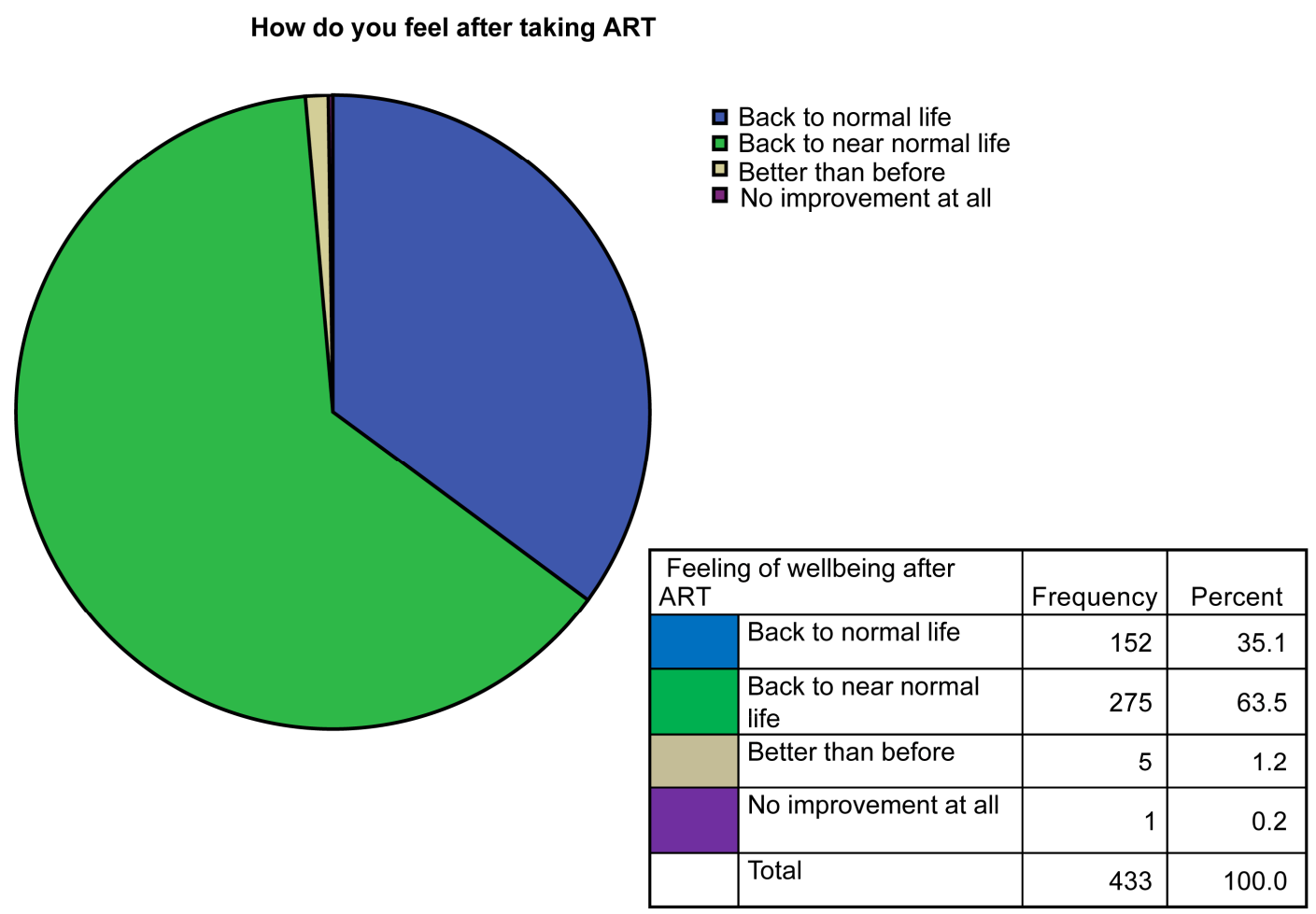

Figure 6. Qualitative wellbeing after ART.

or less than primary schooling. Three fourth of the clients know about ART centre through the government healthcare system which proves the impact of HIV related government programs. Clients who missed their doses need to be addressed to prevent the emergence of resistance and treatment failure [6-12]. One third of the study population is widowed or separated which might have an impact in treatment and prevention strategies due to lack of socio-economic support to them [13]. Sleep disturbances noted in this population is high compared to other psychological problems. Psychological problems, Pill burden/pill fatigue and missed doses in this population which may affect immunity and adherence needs focused counseling which includes coping strategies on these issues [14-28].

\section{Conclusion}

This study supports effectiveness of free ART program and effective case referral from government institutions through Integrated Counseling and Testing Centers (ICTC). High percentage of major or minor psychological problem warrants further exploratory study and may need psychological interventions including targeted counseling in this population.

\section{REFERENCES}

[1] National AIDS Control Organization, “Anti-Retroviral
Treatment: A New Initiative,” 2010.

http://www.nacoonline.org/Quick_Links/Directory/direct ory_ARV/

[2] National AIDS Control Organization, "Prevention Strategies,” 2010.

http://www.nacoonline.org/National_AIDS_Control_Prog ram/Prevention_Strategies/

[3] R. N. Alves, M. J. Kovacs, R. Stall and V. Paiva, "Psychosocial Aspects of HIV Infection among Women in Brazil,” Revista de Saúde Pública, Vol. 36, No. 4, 2002, pp. 32-39. doi:10.1590/S0034-89102002000500006

[4] S. Floyd, A. C. Crampin, J. R. Glynn, M. Mwenebabu, S. Mnkhondia, B. Ngwira, B. Zaba and P. E. Fine, "The Long-Term Social and Economic Impact of HIV on the Spouses of Infected Individuals in Northern Malawi," Tropical Medicine \& International Health, Vol. 13, No. 4, 2008, pp. 520-531.

doi:10.1111/j.1365-3156.2008.02030.x

[5] National AIDS Control Organization, "FAQs on Sexual and Reproductive Health,” 2010. http://www.nacoonline.org/Quick_Links/FAQs/

[6] V. Cambiano, F. C. Lampe, et al., "Long-Term Trends in Adherence to Antiretroviral Therapy from Start of HAART," AIDS, Vol. 24, No. 8, 2010, pp. 1153-1162.

[7] K. Van Vaerenbergh, "Study of the Impact of HIV Genotypic Drug Resistance Testing on Therapy Efficacy," Verhandelingen-Koninklijke Academie voor Geneeskunde van België, Vol. 63, No. 5, 2001, pp. 447-473.

[8] A. Palepu, M. W. Tyndall, K. Chan, E. Wood, J. S. Mon- 
taner and R. S. Hogg, "Initiating Highly Active Antiretroviral Therapy and Continuity of HIV Care: The Impact of Incarceration and Prison Release on Adherence and HIV Treatment Outcomes,” Antiviral Therapy, Vol. 9, No. 5, 2004, pp. 71371-71379.

[9] F. Gutierrez, S. Padilla, M. Masiá, et al., "Clinical Outcome of HIV-Infected Patients with Sustained Virologic Response to Antiretroviral Therapy: Long-Term FollowUp of a Multicenter Cohort,” PLoS One, Vol. 20, No. 1, 2006, p. e89. doi:10.1371/journal.pone.0000089

[10] C. D. Evans, D. T. Eurich, D. A. Lamb, et al., "Retrospective Observational Assessment of Statin Adherence among Subjects Patronizing Different Types of Community Pharmacies in Canada," Journal of Managed Care Pharmacy, Vol. 15, No. 6, 2009, pp. 4764-4784.

[11] J. B. Nachega, M. Hislop, D. W. Dowdy, et al., "Adherence to Nonnucleoside Reverse Transcriptase InhibitorBased HIV Therapy and Virologic Outcomes," Annals of Internal Medicine, Vol. 146, No. 8, 2007, pp. 564-735

[12] A. M. Geretti, C. Smith, A. Haberl, et al., "Determinants of Virological Failure after Successful Viral Load Suppression in First-Line Highly Active Antiretroviral Therapy,” Antiviral Therapy, Vol. 13, No. 7, 2008, pp. 927936.

[13] S. C. Kalichman, M. DiMarco, J. Austin, W. Luke and K. DiFonzo, "Stress, Social Support, and HIV-Status Disclosure to Family and Friends among HIV-Positive Men and Women," Journal of Behavioral Medicine, Vol. 26, No. 4, 2003, pp. 315-332. doi:10.1023/A:1024252926930

[14] L. Persson, B. Gullberg, B. S. Hanson, T. Moestrup and P. O. Ostergren, "HIV Infection: Social Network, Social Support, and CD4 Lymphocyte Values in Infected Homosexual Men in Malmö, Sweden,” Journal of Epidemiology \& Community Health, Vol. 48, No. 6, 1994, pp. 580-585. doi:10.1136/jech.48.6.580

[15] L. V. Edwards, "Perceived Social Support and HIV/ AIDS Medication Adherence among African American Women," Qualitative Health Research, Vol. 16, No. 5, 2006, pp. 679-691. doi:10.1177/1049732305281597

[16] J. Leserman, D. O. Perkins and D. L. Evans, "Coping with the Threat of AIDS: The Role of Social Support," American Journal of Psychiatry, Vol. 149, 1992, pp. 1514-1520.

[17] D. O. Perkins, E. J. Davidson, J. Leserman, D. Liao and D. L. Evans, "Personality Disorder in Patients Infected with HIV: A Controlled Study with Implications for Clinical Care,” American Journal of Psychiatry, Vol. 150, No. 2, 1993, pp. 309-315.

[18] T. M. Wolf, P. M. Balson, et al., "Relationship of Coping Style to Affective State and Perceived Social Support in
Asymptomatic and Symptomatic HIV-Infected Persons: Implications for Clinical Management," Journal of Clinical Psychiatry, Vol. 52, No. 4, 1991, pp. 171-173.

[19] K. I. Pakenham and M. Rinaldis, "The Role of Illness, Resources, Appraisal, and Coping Strategies in Adjustment to HIV/AIDS: The Direct and Buffering Effects,” Journal of Behavioral Medicine, Vol. 24, No. 3, 2001, pp. 259-279. doi:10.1023/A:1010718823753

[20] P. Williams, L. Narciso, et al., "The Prevalence, Correlates, and Costs of Depression in People Living with HIV/AIDS in Ontario: Implications for Service Directions," AIDS Education and Prevention, Vol. 17, No. 2, 2005, pp. 119-130. doi:10.1521/aeap.17.3.119.62903

[21] U. Sambamoorthi, J. Walkup, M. Olfson and S. Crystal, "Antidepressant Treatment and Health Services Utilization among HIV-Infected Medicaid Patients Diagnosed with Depression,” Journal of General Internal Medicine, Vol. 15, No. 5, 2000, pp. 311-320. doi:10.1046/j.1525-1497.2000.06219.x

[22] S. E. Norman, A. D. Chediak, et al., "Sleep Disturbances in Men with Asymptomatic Human Immunodeficiency (HIV) Infection,” Sleep, Vol. 15, No. 2, 1992, pp. 150155.

[23] L. Ferini-Strambi, A. Oldani, et al., "Slow Wave Sleep and Cyclic Alternating Pattern (CAP) in HIV-Infected Asymptomatic Men,” Sleep, Vol. 18, No. 6, 1995, pp. 446-450.

[24] S. E. Norman, A. D. Chediak, M. Kiel and M. A. Cohn, "Sleep Disturbances in HIV-Infected Homosexual Men," AIDS, Vol. 4, No. 8, 1990, pp. 775-781. doi:10.1097/00002030-199008000-00009

[25] T. G. Heckman, J. Miller, et al., "Thoughts of Suicide among HIV-Infected Rural Persons Enrolled in a Telephone-Delivered Mental Health Intervention," Annals of Behavioral Medicine, Vol. 24, No. 2, 2002, pp. 141-148. doi:10.1207/S15324796ABM2402_11

[26] A. Komiti, F. Judd, et al., "Suicidal Behaviour in People with HIV/AIDS: A Review," Australian and New Zealand Journal of Psychiatry, Vol. 35, No. 6, 2001, pp. 747757. doi:10.1046/j.1440-1614.2001.00943.x

[27] N. A. Cooperman and J. M. Simoni, "Suicidal Ideation and Attempted Suicide among Women Living with HIV/AIDS,” Journal of Behavioral Medicine, Vol. 28, No. 2, 2005, pp. 149-156. doi:10.1007/s10865-005-3664-3

[28] B. Kelly, B. Raphael, F. Judd, et al., "Suicidal Ideation, Suicide Attempts, and HIV Infection," Psychosomatics, Vol. 39, No. 5, 1998, pp. 405-415. 